\title{
Pesquisar com o Território: Algumas Apostas Metodológicas
}

\author{
Anita Guazzelli Bernardes \\ Universidade Católica Dom Bosco, MS, Brasil.
}

Resumo: Este artigo tem o objetivo de discutir possibilidades de investigação no campo da saúde a partir do conceito de território. A proposta é lançar algumas questões que permitam certas trajetórias de investigação quando o foco da problematização é o território em saúde. Articula-se território com metodologia, de modo a pensá-los como tecnologias que, além de contribuírem para avaliação e implementação das políticas, também permitem certos itinerários e performances da pesquisa em saúde. O texto situa-se no campo da Psicologia Social, inspirado nas discussões pós-estruturalistas e dos estudos sociais da ciência. O conceito de território pode tornar-se uma ferramenta de investigação, quando se esteia a pesquisa nos próprios processos de avaliação e implementação que a política de saúde sugere, mas também pode se tornar parte de uma problemática de pesquisa. Isto acontece quando se migra de uma dimensão tecnológica para a composição de um campo social no qual um evento em saúde acontece, focalizando-se a singularidade situada de acontecimentos.

Palavras-chave: Território, Saúde, Indícios, Método, Singularidade.

\section{Researching with the Territory: Some Methodological Bets}

\begin{abstract}
This paper aims to discuss research possibilities in the field of health regarding the concept of territory. The proposal is to investigate some questions that enable a certain research path whenever we think of a health territory. It articulates territory and methodology in order to think about them as technologies that, in addition to contributing to assessing and implementing policies, enable some trajectories and performances in health research. This paper is located in the field of Social Psychology and inspired by post-structuralist discussions and social science studies. The concept of territory may become a research tool whenever the research is based on the very processes of assessment and implementation suggested by the health policy, as well as whenever it becomes part of a research question. This happens whenever there is a migration from a technological dimension to the social field where a health-related event takes place, with focus on the singularity of the events.
\end{abstract}

Keywords: Territory, Health, Evidence, Method, Singularity. 


\title{
Investigar con el Territorio: Algunas Apuestas Metodológicas
}

\begin{abstract}
Resumen: Este artículo tiene el objetivo de discutir posibilidades de investigación en el campo de la salud a partir del concepto de territorio. La propuesta es lanzar algunas cuestiones que permitan ciertas trayectorias de investigación cuando el foco de la problematización es el territorio en salud. Se articula territorio con metodología, para pensarlos como tecnologías que, además de contribuir a la evaluación e implementación de las políticas, también permiten ciertos itinerarios y performances de la investigación en salud. El texto se sitúa en el campo de la Psicología Social, inspirado en las discusiones pos-estructuralistas y los estudios sociales de la ciencia. El concepto de territorio puede convertirse en una herramienta de investigación cuando se trata de la investigación en los propios procesos de evaluación e implementación que la política de salud sugiere, pero también puede convertirse en parte de una problemática de investigación. Esto ocurre cuando se migra de una dimensión tecnológica a la composición de un campo social en el cual un evento en salud ocurre, enfocándose la singularidad situada de acontecimientos.
\end{abstract}

Palabras claves: Território, Salud, Indícios, Método, Singularidad.

Este artigo tem o objetivo de discutir possibilidades de investigação no campo da saúde a partir do conceito de território. A proposta é lançar algumas questões que permitam certas trajetórias de investigação quando o foco da problematização é o território em saúde. A necessidade dessa proposta se dá em razão da centralidade que o território assume no campo das políticas de saúde, sobretudo, aquelas voltadas para a Atenção Básica. Há, no artigo, uma intenção de articular território com metodologia, de modo a pensá-los como tecnologias que, além de contribuírem para avaliação e implementação das políticas, também permitem certos itinerários e performances na saúde, ou seja, trata-se de pensar estratégias metodológicas para operar com o território e pesquisar com o território.

O texto situa-se no campo da Psicologia Social, inspirado nas discussões pós-estruturalistas e dos estudos sociais da ciência; em razão disso, já indica certo vetor de condução da reflexão. Trata-se de uma proposta na qual se considera o método como um itinerário de investigação que se torna possível no ato mesmo de investigar. Ou seja, a proposta do texto é refletir sobre metodologia em pesquisa a partir das diferentes formas que se compõem em um percurso de investigação. Essas diferentes formas, no caso deste texto, fazem-se pelos encontros com o conceito de território. Isso implica um jogo de estabilização tanto do território quanto do próprio método. O território assume diferentes versões por meio de certos procedimentos que se colocam em cena, portanto, diferentes performances; por outro lado, ao assumir diferentes performances, o território torna os próprios procedimentos visíveis e enunciáveis também, nesse caso, performados.

A questão colocada é a relevância de uma proposta como esta, na medida em que tanto território quanto método são temáticas recorrentes nas investigações em saúde e na própria Psicologia Social. Portanto, não se trata de uma temática inédita que indicaria uma problemática ainda não tornada foco de discussões. Porém, se no parágrafo acima se indicou um dos vetores de direcionamento da discussão - o campo teórico no qual ela circula e acontece -, agora se indica outro vetor além desse: quando uma temática entra na esteira de um conjunto de práticas e passa a ser sistematicamente encenada, há que se considerar o que essa própria insistência aponta e produz. Em um rastreamento apenas em uma base de dados como a BVS-PSI, aproximadamente nos últimos 10 anos (2006-2017), encontram-se 2.631 produções sobre território que envolvem bases em ciências da saúde e correlatos, 1.515 artigos no SciELO, 36 teses e 12 livros. Em relação à articulação entre método e Psicologia Social, encontram-se 819 produções em bases em ciências da saúde e áreas correlatas, 171 artigos no SciELO e 134 teses. Quanto à aproximação entre território e método, aparecem 209 produções em bases em ciências da saúde e áreas correlatas, 11 artigos no SciELO e quatro teses.

A questão que se coloca, a partir da relevância de uma discussão, é se, caso a reflexão sobre uma temá- 
tica não tenha um caráter inédito, por que seguir seus rastros e continuar a "falar" sobre ela? E aqui se apresenta um terceiro vetor que se avizinha, sobretudo, das pesquisas no campo da Psicologia Social, no qual se situa esta discussão: há uma variedade de investigações operando com distintos procedimentos de pensamento que, às vezes, inclusive, se sobrepõem em termos estratégicos. Encontramos nesse campo pesquisas genealógicas, cartográficas, etnográficas, por exemplo, que tanto sinalizam o modo de operar com conceitos, ou seja, colocá-los para funcionar, quanto indicam trajetórias, caminhos de um problema de pesquisa. Considerar esses procedimentos de investigação, mas, fundamentalmente, essas estratégias de pensamento é uma aposta em certos modos de fazer pesquisa. São apostas situadas, não apenas porque investigam problemas localizados/datados, mas também porque se fazem como percursos posicionados, por conseguinte, indicam desde o princípio a relação inextrincável entre pesquisa e política (Haraway, 1995). Essa relação direciona a relevância para a compreensão do que uma pesquisa é capaz, ou seja, qual a sua potência em termos de produção de mundos, seu caráter de afetação, e não apenas de aclimatação. Assim sendo, pensar sobre o que a recorrência de uma problemática apresenta é justamente situar a pesquisa no solo de nossa atualidade, portanto, daquilo que nos tornamos.

Para esta discussão, em um primeiro momento, será discutida a metodologia no que se refere a uma trajetória da ciência dos indícios. A partir disso, essa perspectiva de pesquisar com indícios será articulada com o território, apontando um plano de bifurcação deste: espaço geográfico e forma de subjetivação. Com isso, passa-se a considerar os procedimentos de investigação com o território que a própria política de saúde sugere e as possibilidades de tornar o território parte de uma problemática que se aproxime de singularidades situadas.

\section{Percursos metodológicos}

A proposta aqui é pensar alguns elementos que se fazem presentes em certos modos de investigação nessa forma de operar com a Psicologia Social quando esta se torna possível pelas reflexões pós-estruturalistas ou mesmo pelos estudos sociais da ciência. Não se trata de subsumir diferentes autores e criar uma massa indiferenciada que anularia as especificidades de cada um deles, borrando a potência daquilo que os faz diferir, inclusive, em um mesmo campo. Portanto, pensar com Foucault, Deleuze, Latour, Moll, Haraway, mas também Nietzsche e Canguilhem, entre outros, não é esquecer aquilo que os faz diferir entre si e, com isso, aquilo que os "assalta" como problemas, conceitos, objetos que colocam para funcionar. Todos eles são, ao mesmo tempo, caixas de ferramentas e modalidades de espanto, pois justamente nos permitem formas de habitar um campo de investigação e formas de inflexão sobre aquilo mesmo que pesquisamos. Esses autores seguem trajetórias distintas, apostam em jogos de pensamento também diferentes, inventam conceitos que marcam seus corpos, suas ideias, seus mundos. Trata-se de um processo em que um conceito, um objeto e uma problemática assumem um nome próprio, engendrando uma relação simbiótica entre autor-conceito-objeto.

Entretanto, quando se trabalha com eles, acaba-se por pegar ferramentas dessas diferentes caixas, desses diferentes nomes próprios, e monta-se uma caixa própria, ou seja, uma caixa situada. Ao tornar essa caixa localizada, a aposta é justamente fazer da pesquisa um ato de composição e estabilização de outros mundos. O mundo desses autores já se apresenta estabilizado; a questão é como seguir com eles certas trajetórias que permitam um adensamento de problemáticas de nossa atualidade, considerando tanto aquilo que permite aproximá-los entre si, de modo a inventar novos percursos, quanto aquilo que os faz diferir, que permite uma dilatação do próprio modo de pensar. Esses percursos de investigação são nomeados de metodologias/métodos de pensamento. As discussões sobre metodologia/método fazem a própria ciência acontecer, são condições de possibilidade da ciência e, com isso, percorrem e são percorridas naquilo que se considera como processos de cientificização e suas controvérsias em termos de produção de conhecimento, tecnologias e sua função social, como é apontado por Stengers (1993) na análise que faz da produção de autores como Kuhn, Popper, Koyré, Lakatos e Feyerabend, entre outros. Essas controvérsias indicam a latitude da relação entre conhecimento e procedimento, apontando, na realidade, sua relação inextrincável. Portanto, a invenção do conhecimento está condicionada pelo modo como essa invenção torna-se possível, isto é, pelos diferentes mecanismos que fazem um conhecimento acontecer: ferramentas de investigação. As ferramentas de investigação são tanto conceitos quanto técnicas com as quais se investiga. São modos de um pensamento assumir certas formas e com elas 
seguir rastros, caminhos. Há diferentes curvaturas nas discussões metodológicas, de modo geral, que circulam, predominantemente, entre o estabelecimento a priori das ferramentas (ciências da prova) ou a composição com as ferramentas durante os percursos de investigação (ciências do indício).

Essas diferentes curvaturas apontam o modo como o conhecimento é posicionado, situado, no sentido de que cada uma delas se constitui em certas concepções de ciência e de suas implicações, conforme pode ser considerado nos autores supracitados (Haraway, 1995). O debate sobre a ciência não é novo também, portanto, aqui não se estenderá a discussão. A questão que interessa a este texto é, justamente, seguir uma dessas linhas de investigação como estratégia para articular método e território. Trazer essa questão se faz necessário na medida em que evidencia aquilo que Mol (2008) aponta como realidades múltiplas e, como tais, efeitos de intervenções e performances. Isso significa considerar que as diferentes ferramentas, mormente os diferentes modos de operar com elas, produzem diferentes realidades, nas quais não está em jogo qual o melhor percurso/método, e sim qual o posicionamento que se produz no ato de pesquisar. Então, as controvérsias da ciência são controvérsias de percursos, são controvérsias políticas. As controvérsias políticas dizem respeito a escolhas metodológicas que seguem certas trajetórias de investigação. Além disso, apresentam implicações na forma como se produz conhecimento, na medida em que performam certos modos e não outros de como se conhece, o que se conhece, o que se faz com o conhecimento e o que o próprio conhecimento faz no mundo. Portanto, as ferramentas metodológicas são escolhas políticas. Não são escolhas no sentido de varejo, mas escolhas no sentido de implicação. Cada conceito, cada técnica traz consigo um mundo, uma forma de habitar o mundo. Portanto, as caixas de ferramentas tornam-se um ethos da pesquisa, um modo de condução da conduta e da relação desta com a verdade (neste caso, aquilo que se produz como verdade em ciência).

Isso significa considerar o que foi indicado na introdução do texto sobre a insistência de uma temática e o modo de pesquisá-la no que diz respeito ao que produz: pesquisar com o território e no território deixa marcas de percurso, ao mesmo tempo em que se torna a própria condição de existência do território. Assim, este deixa de ser uma realidade em si mesma para tornar-se efeito de um conjunto de articulações que o encenam de forma situada, tornando-o múltiplas reali- dades que permitem que ele seja tanto uma ferramenta de investigação, quando se faz como tecnologia de avaliação em saúde, por exemplo, quanto objeto de pesquisa, quando sobre ele certa trajetória é conduzida. A encenação, nesse caso do território como tecnologia ou como objeto, é fruto dos diferentes modos que as formas de investigação assumem. Além disso, as trajetórias e implicações - território como procedimento e território como objeto - são maneiras de assumir uma dimensão incorporada da pesquisa e da produção de conhecimento, que deverá responder as próprias questões que interrogam a investigação. Seguir itinerários é também acompanhar aquilo que colocará o próprio processo de investigação em análise, por isso um ethos, certa forma de relação com a verdade, e não sujeição ou aclimatação de uma verdade. Interroga-se o mundo com os percursos de pesquisa escolhidos, mas as escolhas de percurso de pesquisa também passam a ser interrogadas por aquilo que produzem.

A escolha aqui, conforme já anunciado, se faz com autores que compõem determinado campo de investigação em Psicologia e também em Saúde - pós-estruturalismo e estudos sociais da ciência. Esses autores, embora não sejam psicólogos e tampouco da área especificamente da saúde, acabaram por ser "raptados" por ambas as áreas como estratégia de produção de novas formas de argumentação, seja na ciência psicológica, seja na saúde, para "prolongar, reinventar, recomeçar com outros dados", como sugere Stengers (1993, p. 84) quando relata suas escolhas a respeito das investigações sobre a guerra das ciências. Uma das qualidades da composição com esse campo de exterioridade à ciência psicológica e à saúde é sua capacidade de dilatação e latitude de problemáticas e de eventos que passam a existir como problemas de nossa atualidade. Tais autores produzem algumas torções no pensamento e, com isso, potencializam uma investigação situada, implicada. Além disso, também são autores que comportam o uso de outros órgãos de sentidos, que não apenas o olhar. Aliás, mais do que o uso de outros órgãos dos sentidos, esses autores estrangeiros permitem a efetuação de um corpo do pesquisador, que aprende a ser afetado por aquilo que anteriormente não o fazia agir, sentir, falar - produzem "simultaneamente um meio social e um mundo sensível" (Latour, 2008, p. 40) mediante o qual se tornam possíveis certos itinerários.

Tornar-se um corpo que pesquisa, por meio dessas aprendizagens com esses autores, é ter uma capacidade sensível para outras realidades que se 
performam a partir da afetação da ciência psicológica e da saúde pela filosofia, sociologia, história, feminismo, geografia etc. É justamente deslocar-se do purismo disciplinar. Esse deslocamento ou borramento de fronteiras disciplinares permite novas curvaturas, desvios, mudanças de percurso; seria, assim, um modo de invenção de novas normas/itinerários/ procedimentos, como aponta Canguilhem (2012) quando se interrogou sobre a vida e considerou que, ao mesmo tempo em que ela se sujeita às normas, também inventa novas normas.

Trabalhar com indícios ou, mais especificamente, com o rastreio de indícios é indicado por Ginzburg (2016) como uma atividade que reporta o pesquisador aos movimentos de um caçador e ao trabalho de tecelagem. Em ambas as ações, entram em jogo tanto o rastreio de um campo por meio da acuidade das sensibilidades a diferentes marcas que certos eventos nele deixam - no caso do caçador, os rastros que ele segue-, quanto à percepção de diferentes fios na homogeneidade de um tecido - como na tecelagem. Neste caso, trata-se de um exercício de redução de escala de observação, em que uma superfície coerente começa a ser percebida como efeito de uma urdidura. Marcas e fios passam a compor, em uma investigação de indícios, um campo no qual o ato de pesquisar começa a adquirir consistência, que se dá mais pelos detalhes do que propriamente por uma suposta totalidade.

Ginzburg (2016) faz uma análise de textos de Morelli, crítico de arte italiano do século XIX que, para o exercício de sua atividade de atribuição autoral, indicava que: "deveríamos, sim, concentrar-nos em detalhes menores, especialmente aqueles menos significativos no estilo típico da escola do pintor: os lóbulos das orelhas, as unhas, as formas dos dedos, das mãos, dos pés" (p. 15). Aqui, então, o indício não é uma evidência, mas uma singularidade localizada, um plano "menor". Esse plano menor ganha consistência justamente pela articulação entre diferentes indícios, que vão, com o ato de pesquisar, assumindo certas relações, certas composições.

O que se quer apontar com isso é que um indício apenas assume condição como tal quando articulado, portanto, encenado. O indício existe por meio de suas conexões; não é uma existência isolada, mas uma existência articulada que permite que ele se torne justamente um indício. Explica-se: para que algo seja considerado como indício de uma singularidade, o processo não é isolar um determinado evento em si mesmo para provar que este existe, mas percorrer o solo que torna possível que esse indício apareça, aconteça. Esse solo é composto de conceitos e de outros eventos. Quando um caçador se depara com um galho quebrado, essa percepção do galho quebrado só é possível porque um galho se compõe com a estrutura de uma planta, além de uma estrutura que o quebra de determinada forma, e não o amassa, por exemplo; o galho também é percebido porque o próprio caçador tem certo "corpo" para atentar aos galhos, ou seja, tem um conceito com o qual caminha, que o acompanha em termos de sensibilidade aos galhos.

O indício, portanto, é efeito de um conjunto de articulações que o fazem perceptível e ao mesmo tempo indicador de certo percurso a seguir. Neste caso, o indício, como um coletivo articulado (galho-planta-conceito, por exemplo), não é um evento escondido que deva ser escavado para ser descoberto, mas um fio de uma urdidura que permite que uma sensibilidade percorra um campo ao seguir certos rastros que vão aproximando outros indícios. O indício não está escondido, está em uma superfície plana, porém, como em um tecido, ao se olhar essa superfície, as singularidades, a princípio, não aparecem. As singularidades passam a aparecer à medida que um corpo vai se compondo em termos de acuidade das sensibilidades: as diferenças de sons, de odores, de formas, de texturas, são passíveis de serem experimentadas com os movimentos de aproximação e distanciamento que um corpo faz ao seguir com os rastros que os indícios vão tornando possíveis. Seguir indícios é considerar detalhes marginais no percurso de investigação, eventos triviais pouco importantes e às vezes imperceptíveis, por sua qualidade ordinária, casual.

Essa atenção ao detalhe como indício torna-se importante porque indica outro campo de composições de um problema; especialmente, aponta para o caráter localizado de um determinado problema e suas condições de articulação e performance (Haraway, 1995; Mol, 2008). O indício, aqui, não é o elemento pequeno que faz parte de um todo, mas um elemento que indica um acontecimento, por isso sua condição de singularidade. Indica um acontecimento porque começa a ser percebido como algo que difere, que assume consistência, densidade, saindo de uma região de opacidade. Dessa forma, a insistência de pesquisas sobre território permite considerar esses deslocamentos que o próprio território produz em um campo social. 


\section{Território e itinerários com indícios}

O conceito de território apresenta um plano de bifurcação: é ao mesmo tempo uma estratégia de planificação, de organização e de localização de determinado evento, comunidade, população, portanto, uma superfície geográfica, e um conceito que Deleuze e Parnet (1998) propõem para a compreensão de modos de subjetivação. Além disso, na saúde, o território assume a condição de uma tecnologia de avaliação, implementação e regulação do acesso à saúde.

É interessante considerar algumas questões que Haesbaert (2013, p. 120) escreve: "o território é uma invenção política do mundo moderno". Como invenção moderna, especialmente como estratégia da modernidade que emerge no campo da geografia, mas que se encontrará com o campo da saúde e das ciências sociais e humanas, o território vai assumindo diferentes versões, de acordo com os modos com os quais compõe certas possibilidades de organização social e controle das circulações, sejam elas das populações, das riquezas, das epidemias, enfim, daquilo que começa a ser foco de investimentos e regulação com a governamentalidade dos Estados modernos (Foucault, 2008). O território assume, assim, uma condição relevante para organizar, conhecer, circunscrever, localizar, seguindo certo desafio que Haesbaert (2013, p. 14) aponta: "como no mundo contemporâneo vive-se concomitantemente uma multiplicidade de escalas, numa simultaneidade atroz de eventos, vivenciam-se também, ao mesmo tempo, múltiplos territórios".

Seja como escala espacial, como modo de subjetivação, como estratégia política e econômica, o território vai se adensando, portanto, tornando-se múltiplos territórios. Esse adensamento é efeito, conforme escrito, de diferentes performances, o que não diminui sua potência de intervenção no mundo e nas próprias trajetórias de pesquisa. Há uma condição importante do território que diz respeito à experiência de espaço, que tanto pode ser "natural" quanto "social". O território, assim, permite certa possibilidade de localização, não apenas porque indica um lugar, mas também porque situa certo acontecimento. Neste caso, o território traria uma superfície mediante a qual é possível pensar um movimento do acontecimento de modo situado. Um movimento situado, por meio do território, permite um itinerário no tempo e no espaço. $\mathrm{O}$ movimento aproxima duas dimensões de experiência que se constituem por meio de uma relação de reciprocidade: algo se passa em uma determinada loca- lização. Esse algo que se passa em uma determinada localização pode, mediante certas estratégias, itinerários e sensibilidades, ser experimentado como singularidade. Perceber que algo se passa situa a investigação em um tempo, em um espaço, tornando a própria investigação um plano de abertura para acompanhar os rastros que o movimento vai deixando.

Muito além de ser meramente o espaço político-operativo do sistema de saúde, o território do distrito sanitário ou do município, onde se verifica a interação população-serviços no nível local, caracteriza-se por uma população específica, vivendo em tempo e espaço determinados, com problemas de saúde definidos e que interage com os gestores das distintas unidades prestadoras de serviços de saúde (Monken, \& Barcelos, 2005, p. 898).

A condição de articulação de tempo e espaço não significa subsumir um ao outro, mas operar com ambos. Situar o território como um elemento fundamental para, no caso da saúde, conhecer os movimentos da população no tempo e no espaço, implica um itinerário, seja ele de avaliação, de implementação ou regulação, que acompanhe tanto certos rastros físicos, como aquelas marcas que se fazem em uma superfície espacial, quanto certos rastros temporais, ou seja, aquelas marcas deixadas em um plano de duração de eventos, de acontecimentos que contam histórias de vida. Essa composição de tempo e espaço pelo território, além de permitir uma experiência geográfica de localização, possibilita uma experiência de temporalidade do vivido. A bifurcação do conceito de território, conforme escrito acima, se performa nesse avizinhamento que o movimento produz. Faz-se tanto por localização quanto por subjetivação. Entende-se, nesse caso, que localização não se refere exclusivamente ao espacial, assim como a subjetivação não se refere apenas ao temporal. Operar com a bifurcação do território é seguir rastros situados no tempo e no espaço que constituem um plano de experiência situada, portanto, modalidades mediante as quais a população, por exemplo, se torna reconhecível como tal. O reconhecível diz respeito aos modos de viver, de circular, enfim, de movimentar corpos e com eles deixar marcas como modos de subjetivação: "um perfil demográfico, epidemiológico, administrativo, tecnológico, político, social e cultural, que o caracteriza como um território em permanente construção" (Monken, \& Barcelos, 2005, p. 899). 
Entretanto, é relevante considerar como essa bifurcação do território recai no campo da saúde. De acordo com Moraes e Canôas (2013), não há um consenso sobre o conceito de território na saúde, especialmente no que se refere à questão geográfica/ espacial; porém, apesar disso, há uma insistência da estratégia, seja ela como categoria mesma de localização, ou de operacionalização (NOBs e NOAS), ou de atuação (ESF), sendo que uma não exclui a outra, mas faz o território multiplicar-se. A ausência de consenso sobre o conceito, a princípio, pode apresentar-se como uma fragilidade da própria política, mas, seguindo o que foi escrito anteriormente sobre uma ciência do rastreio, essa multiplicidade que o performa torna possível acompanhar diferentes versões que assume e, com isso, diferentes agenciamentos com os quais se encontra. Os agenciamentos tomam aqui a condição de planos de composição, ou seja, de fios que são urdidos por meio de diferentes práticas.

É possível seguir indícios do território quando este se compõe como distrito sanitário, área, microárea, região, entre outros que permitem um esquadrinhamento espacial para a distribuição e acesso a serviços, por exemplo. Também é possível acompanhá-lo quando se articula às formas de operacionalização da descentralização e regionalização em saúde, de modo a permitir estratégias de vigilância em saúde e respostas às necessidades de saúde de forma localizada. Além disso, o território constitui-se pela relação com dimensões de escalas, como aquelas que se fazem pela vinculação das equipes de saúde diretamente com a população, no caso das equipes de saúde da família. Aqui, o território encontra-se com indícios mais sutis e singulares, com os acontecimentos ordinários do cotidiano que dizem respeito aos movimentos específicos de cada sujeito, grupo, comunidade, em um determinado tempo-espaço.

Essas três composições do território permitem percursos distintos e escalas de afetação também diferentes. São planos de composição do território que o fazem aparecer em uma dimensão tanto macropolítica quanto micropolítica, mas permanentemente situadas. São situadas porque em nenhuma delas o território existe por si só; em todas, a condição de existência do território se faz pelos encontros que o tornam possível - localização, operacionalização, atuação. Os indícios dessas articulações, por exemplo, permitem acompanhar certas conformações do território por meio de diferentes estratégias e sensibilida- des: pode ser pela análise das próprias políticas; pela análise de dados demográficos, epidemiológicos, econômicos, culturais etc.; pelas formas de vinculação e adscrição da população com as equipes. Nesse caso, o território torna-se, para a investigação, uma superfície mediante a qual é possível percorrer e acompanhar seus indícios em termos de articulações e movimentos que a política de saúde produz.

O que se quer apontar com isso é que o território, como tecnologia, no âmbito da implementação da política de saúde, opera por meio de processos de territorialização, o que "consiste em um dos pressupostos da organização dos processos de trabalho e das práticas de saúde, considerando-se uma atuação em uma delimitação espacial previamente determinada" (Monken, \& Barcelos, 2005, p. 898). Além disso, ainda no que tange à política de saúde, o território assume a dimensão de objeto de avaliação, e é sobre ele que se articulam as necessidades e respostas em saúde, trajetórias de cuidado e população. O que está em jogo como tecnologia e como objeto na saúde é a condição que o território assume de visibilidade de determinados acontecimentos de saúde, trajetórias na rede de cuidados e operacionalização dos serviços de saúde. Isso pode torná-lo um itinerário interessante no âmbito das investigações que se voltam para problemáticas em saúde, ou seja, a própria política de saúde oferece pistas a serem acompanhadas por um percurso de investigação. Nesse caso, pesquisa-se com a própria política de saúde, e não sobre a política de saúde. O conceito de território da política de saúde torna-se um elemento que permite seguir certos rastros. Não se trata de estabelecer o território como um a priori metodológico, mas como recursos possíveis para seguir uma problemática em pesquisa. O conceito de território, no caso, é um modo de pesquisar que permite formas de pensar e de interrogar em pesquisa.

Por outro lado, o território também pode assumir a condição de parte de uma problemática de um acontecimento na saúde; portanto, aqui, deixa de ser em si um conceito/ferramenta para tornar-se também uma pista, mas agora como parte de um conjunto heterogêneo do qual irá aproximar-se. O território afasta-se de sua dimensão tecnológica para assumir a condição de uma problemática ou objeto de pesquisa. Não opera em termos de rastros passíveis de serem seguidos, mas de rastros que deixam marcas na conformação de certa problemática de pesquisa. Se, no pri- 
meiro caso, tratava-se de uma ferramenta do caçador, agora é um dos fios de uma urdidura.

O território como possibilidade tecnológica de investigação e como problemática, dentro do campo de discussões em que foi situado o texto, apresenta nas montagens de investigação uma dimensão que é importante para essas modalidades de pesquisa situadas: a singularidade dos acontecimentos, mas especialmente quando o território se faz como parte de um acontecimento em saúde, a dimensão de acesso às singularidades torna-se interessante como plano de composição, isto é, urdir território com outros eventos em saúde cria um plano de singularização do acontecimento. Isso acontece não apenas porque o território permite a localização de um movimento no tempo-espaço, mas porque com ele é possível caminhar com uma problemática de modo a se acessar uma escala menor onde a vida se passa. Essa escala menor é aquela dos eventos do cotidiano, aqueles eventos que, por sua regularidade, acabam muitas vezes tornados invisíveis. São eventos que não marcam os grandes acontecimentos da história e da saúde, mas marcam os acontecimentos das vidas vividas em ato: por exemplo, as diferentes formas de negociação que um determinado grupo/comunidade estabelece com as ações em saúde; os diferentes lugares que as pessoas buscam para responder às suas necessidades de saúde; os diferentes usos das tecnologias em saúde pela população; as diferentes situações em que as pessoas buscam os serviços de saúde.

Ginzburg (2006, p. 11) sugere algumas questões interessantes em relação à noção de singularidades e às possibilidades de investigação:

no passado, podiam-se acusar os historiadores de querer conhecer somente as "gestas dos reis". Hoje, é claro, não é mais assim. Cada vez mais, interessam-se pelo que seus predecessores haviam ocultado, deixado de lado ou simplesmente ignorado. "Quem construiu Tebas das sete portas?" - perguntava o "leitor operário" de Brecht. As fontes não nos contam nada daqueles pedreiros anônimos, mas a pergunta conserva todo seu peso.

O peso da pergunta sobre essas existências anônimas, sobre essas vidas que não deixam marcas formais sobre sua própria história, torna-se, no campo da Psicologia Social, uma dimensão fundamental para a compreensão do que se passa com a vida. Ginzburg (2006) percorre um território em que os indícios de certas existências são praticamente inexistentes, mas a orientação para compreender, no caso de sua pesquisa, certo culto de raízes agrárias pagãs que foi transformado pela Inquisição em um ritual diabólico acaba por colocar em cena uma existência que não aparecia, uma existência escurecida por diferentes estratégias de produção de verdades, de produção de história. Mais do que o culto em si, a trajetória do pesquisador permitiu seguir rastros singulares de vidas que passaram:

Este livro conta a história de um moleiro friulano - Domenico Scandella, conhecido por Menocchio - queimado por ordem do Santo Ofício, depois de uma vida transcorrida em total anonimato. A documentação dos dois processos abertos contra ele, distantes quinze anos um do outro, nos dá um quadro rico de suas ideias e sentimentos, fantasias e aspirações. Outros documentos nos fornecem indicações sobre suas atividades econômicas, sobre a vida de seus filhos. Temos também algumas páginas escritas por ele mesmo e uma lista parcial de suas leituras (sabia ler e escrever) (Ginzburg, 2006, p. 11).

Esses indícios percorridos em um território por meio de documentos que marcam o que Foucault (2003) consideraria como os breves contatos que certas vidas infames têm com o poder e, com isso, passam a existir em algumas breves linhas deixam rastros que permitem compreender o que se passa em um nível micropolítico. Esse nível micropolítico é a dimensão do detalhe mediante o qual se constituem formas de subjetivação, ou seja, formas de territorialização da vida em seu desenrolar. As singularidades dos acontecimentos abrem um campo de visibilidades tanto para as diferentes estratégias que as silenciam, quanto para as estratégias que marcam a insistência dessas vidas em continuar existindo. As estratégias que silenciam e as insistências em existir são indícios de um jogo político que se produz com o território.

\section{Algumas considerações}

A proposta do artigo de discutir possibilidades de investigação no campo da saúde pela Psicologia Social a partir do conceito de território é percorrida 
no texto pela apresentação de uma forma de investigação que se apoia em uma ciência dos indícios. Os indícios assumem a potência de seguir rastros de acontecimentos singulares e, portanto, situados. A dimensão da singularidade situada para os processos de investigação significa um percurso metodológico implicado. Seguir indícios é articular o corpo do pesquisador com o universo que pesquisa. Desse modo, o conceito de território pode tornar-se uma ferramenta de investigação tanto quando se esteia a pesquisa nos próprios processos de avaliação e implementação que a política de saúde sugere, quanto quando se torna parte de uma problemática de pesquisa, migrando de uma dimensão tecnológica para a composição de um campo social no qual um evento em saúde acontece. Em ambas as condições em que o pesquisar com o território se oferece ao pesquisador, está em jogo a acuidade de diferentes sensibilidades, a articulação com diferentes conceitos para a composição de mundos, portanto, de performances que fazem certas invisibilidades ser encenadas e passar, assim, a existir.

\section{Referências}

Canguilhem, G. (2012). O conhecimento da vida. Rio de Janeiro, RJ: Forense Universitária.

Deleuze, G., \& Parnet, C. (1998). Diálogos. São Paulo, SP: Escuta.

Foucault, M. (2003). A vida dos homens infames. In M. Foucault, Ditos \& Escritos IV (pp. 203-222). Rio de Janeiro, RJ: Forense Universitária.

Foucault, M. (2008). Segurança, território, população. São Paulo, SP: Martins fontes.

Ginzburg, C. (2006). O queijo e os vermes. São Paulo, SP: Companhia das Letras.

Ginzburg, C. (2016). Morelli, Freud e Sherlock Holmes: indícios e método científico. Portugal: Deriva.

Haesbaert, R. (2013). Territórios alternativos. São Paulo, SP: Contexto.

Haraway, D. (1995). Saberes localizados: A questão da ciência para o feminismo e o privilégio da perspectiva parcial. Cadernos Pagu, (5), 7-41.

Latour, B. (2008). Os estudos sobre a ciência em perspectiva. In J. A. Nunes, \& R. Roque (Orgs.), Objectos impuros: Experiências em estudos sobre a ciência (pp.37- 61). Porto: Afrontamento.

Mol, A. (2008). Política ontológica. Algumas ideias e várias perguntas. In J. A. Nunes, \& R. Roque (Orgs), Objectos Impuros: Experiências em estudos sobre a Ciência (pp. 63- 77). Porto: Afrontamento.

Monken, M., \& Barcellos, C. (2005). Vigilância em saúde e território utilizado: Possibilidades teóricas e metodológicas. Cadernos de Saúde Pública, 21(3), 898-906. https:// doi.org/10.1590/S0102-311X2005000300024

Moraes, D. E., \& Canôas, S. S. (2013). O conceito de "território" e seu significado no campo da atenção primária a saúde. Revista Desenvolvimento Social, 1(9), 49-57.

Stengers, I. (1993). As políticas da razão: Dimensão social e autonomia da ciência. Lisboa: Edições 70.

\section{Anita Guazzelli Bernardes}

Docente e Pesquisadora do Programa de Pós-Graduação em Psicologia e do Programa de Pós-Graduação do Desenvolvimento Local da Universidade Católica Dom Bosco. Coordenadora do Programa de Pós-Graduação em Psicologia da Universidade Católica Dom Bosco. Pesquisadora do CNPq - Bolsista Produtividade. Campo Grande - MS. Brasil

E-mail: anitabernardes1909@gmail.com

Endereço para envio de correspondência:

Avenida Tamandaré, 6000, Jardim Seminário. CEP: 79117-900

Campo Grande - MS. Brasil. 
Psicologia: Ciência e Profissão Abr./Jun. 2018 v. 38 n², 291-300.

Recebido 23/08/2017

Aprovado 12/01/2018

Received 23/08/2017

Approved 01/12/2018

Recibido 23/08/2017

Aceptado 12/01/2018

O artigo contou com financiamento do CNPQ.

Como citar: Bernardes, A. G. (2018). Pesquisar com o território: Algumas apostas metodológicas. Psicologia: Ciência e Profissão, 38(2), 291-300. https:// doi.org/10.1590/1982-3703003492017

How to cite: Bernardes, A. G. (2018). Researching with the territory: Some methodological bets. Psicologia: Ciência e Profissão, 38(2), 291-300. https:// doi.org/10.1590/1982-3703003492017

Cómo citar: Bernardes, A. G. (2018). Investigar con el territorio: Algunas apuestas metodológicas. Psicologia: Ciência e Profissão, 38(2), 291-300. https:// doi.org/10.1590/1982-3703003492017 